\title{
Evaluation of Information and Communication Technology Systems for Healthcare Provision in Low \& Middle Income Countries
}

\author{
Samuel T. Mbugua ${ }^{1}$, David M. Gichoya ${ }^{2}$, Dr. Damaris N. Odero ${ }^{3}$ \\ ${ }^{1}$ Moi University, School of Information Sciences, Department of Information Technology, Kenya \\ ${ }^{2}$ Professor, Moi University, School of Information Sciences, Department of Information Technology, Kenya \\ ${ }^{3}$ Moi University, School of Information Sciences, Department of Library, Records Management and Information Studies, Kenya
}

\begin{abstract}
In order to make appropriate decisions while providing care to a patient, a healthcare provider needs to be furnished with all necessary information. This information will be captured, processed, stored and exchanged using various information management systems. Applying ICT in these systems requires considerable investments in terms of infrastructure and human skill which is faced with inadequate resources In Low and Middle Income countries. Hence, this study sought to assess the effectiveness and efficiency experienced by the healthcare sector due to application of ICT systems in healthcare. Specifically the study sought to: determine the type of systems used to manage health information; establish the challenges inherent in the healthcare information systems and recommend measures to mitigate the challenges inherent in the current systems. The study adopted a mixed method research approach utilizing a case study. The study targeted a population of 82 respondents where 34 were sampled comprising of 3 Clinical Officers, 2 Doctors, 2 Laboratory Technicians, 10 Nurses, 10 Patients, 3 Pharmacists, 3 Records Officers and 1 ICT Staff. Purposive sampling was used to draw out all the providers and informatician target while simple random and purposive sampling was used to draw out the 10 patients. Data was collected through interviews, questionnaires and documentary reviews. Quantitative data was subjected to descriptive statistics while qualitative data was analyzed thematically. The study established that manual and computerised systems are under use by Kabarak University Health Centre to record/capture patient information in an episode of care and that records, consultation, laboratory, and pharmacy sections have been computerized. It was also established that ICT is being employed in the provision of healthcare in Low and Middle income countries but that challenges exist in their adoption and use. The study therefore recommended increased investments in ICT infrastructure; adoption of mobile technology to further accessibility of healthcare information and enactment of enabling HIS policies and awareness creation.
\end{abstract}

Keywords: HIS, Healthcare, ICT, ICT Infrastructure, Low and Middle Income Countries, Patient, Provider

\section{Introduction}

With an increasing population, changing life styles and globalization effects, heath care providers in Low and Middle Income Countries (LMIC) are more than ever working in increasingly complex clinical environments. This has lead to adoption and use of ICTs in order to increase the effectiveness and efficiency of healthcare service delivery systems. However, their widespread use is inhibited by lack of robust ICT infrastructure arising from limited finances and human skill.

According to [1], the complexity of clinical practice has increased dramatically in recent years, with patients having more chronic illnesses, taking more medications, health care staff being required to work in more complex teams and requiring more information for providers to make informed clinical decisions.

Further, WHO notes that the application of ICT in health is not just about technology, but can be a means to realization of the following outcomes: health workers making better treatment decisions, hospitals providing higher quality and safer care, governments becoming more responsive to health needs, national and local information systems supporting the development of effective, efficient and equitable health systems, and people having better access to the information and knowledge they need for better health hence making informed choices about their own health [2].

Thus, this can be solved if the healthcare institutions put in place the necessary e-health systems to aid the few providers in the process of data acquisition and subsequent decision making.

\section{Aim}

The aim of the study was to assess the application of ICT in healthcare provision in low resource settings.

\section{Objectives}

a) To determine the type of systems used to manage health information;

b) To establish the challenges inherent in the healthcare information systems;

c) To recommend measures to mitigate the challenges inherent in the current systems.

\section{Health Information Technology}

Electronic healthcare (e-health) refers to the organization and delivery of health services and information using internet and related technologies. E-health is not only a technical development but also a new way of working, an attitude, and

Volume 6 Issue 7, July 2017 www.ijsr.net 


\section{International Journal of Science and Research (IJSR) \\ ISSN (Online): 2319-7064}

Index Copernicus Value (2015): 78.96 | Impact Factor (2015): 6.391

a commitment to networked, global thinking so as to improve healthcare locally, regionally and globally by use of information communication technology [3]. Health information technology (HIT) encompasses a wide range of products and services - including software, hardware and infrastructure - designed to collect, store and exchange patient data throughout the clinical practice of medicine, [4]. According to [5], the most recognised source of inefficiency in health care system is the fragmentation of the care delivery process and the poor transfer of information. This is as confirmed by the Kenyan Ministry of Health in it's HIS policy of 2009, [6];

"...health Information is not integrated with information technology to the extent witnessed in developed countries. This is attributed to the limited availability of the requisite skills and equipment at the various levels and the high levels of IT illiteracy".

To mitigate these challenges, Low and Middle Income Countries need to implement integrated health systems that provide information to the various stakeholders in timely and accurate format while maintaining confidentiality, availability and privacy of this information.

In Kenya for instance, the application of information and communication technology (ICT) in the health sector aims to simplify administrative processes and reduce data gathering and processing costs and to facilitate the delivery of health related information to remote locations within the sector. However, as the use of ICT and the exchange of electronic health information increases, concerns about the protection of personal health information exchanged electronically within a nationwide health information network will also increase, HIS Policy [6].

Further, Electronic Medical Record (EMR) systems are increasingly being adopted in Kenya to improve medical records management, health program management and the quality of patient care. It is however worthy to note that the development and implementation of EMRs has not been properly coordinated, resulting in multiple EMRs with varying objectives and functionality and with no ability to share patient information with other systems, programs and the Government, Standard \& Guidelines for EMRs in Kenya [7].

According to [8], an EHR has four domains and each domain has different number of functions which qualifies an EHR system as either basic or fully functional. This is as illustrated in Table 1.

Table 1: Functional characteristics of a basic and fully functional EHR system

\begin{tabular}{|c|c|c|c|c|}
\hline S/N & Functions & $\begin{array}{c}\text { Number } \\
\text { of } \\
\text { functions }\end{array}$ & \multicolumn{2}{|l|}{ Nature of functions } \\
\hline & & & $\begin{array}{c}\text { Basic } \\
\text { system }\end{array}$ & $\begin{array}{c}\text { Fully } \\
\text { functional } \\
\text { system }\end{array}$ \\
\hline \multirow{4}{*}{1} & Health Information and data & Five & & \\
\cline { 5 - 5 } & Patient demographics & & $\times$ & $\times$ \\
\cline { 2 - 3 } & Patient problem lists & & $\times$ & $\times$ \\
\cline { 2 - 3 } \cline { 4 - 5 } & & & $\times$ & $\times$ \\
\hline
\end{tabular}

\begin{tabular}{|c|c|c|c|c|}
\hline \multirow[t]{4}{*}{$\mathrm{S} / \mathrm{N}$} & Functions & $\begin{array}{c}\text { Number } \\
\text { of } \\
\text { functions }\end{array}$ & \multicolumn{2}{|c|}{ Nature of functions } \\
\hline & taken by patients & & & \\
\hline & Clinical notes & & $x$ & $x$ \\
\hline & $\begin{array}{l}\text { Notes including medical } \\
\text { history and follow up }\end{array}$ & & & $x$ \\
\hline \multirow[t]{6}{*}{2} & Order- entry management & Five & & \\
\hline & Orders for prescription & & $x$ & $x$ \\
\hline & Orders for laboratory tests & & & $x$ \\
\hline & Orders for radiology tests & & & $x$ \\
\hline & Prescription sent electronically & & & $x$ \\
\hline & Orders sent electronically & & & $x$ \\
\hline \multirow[t]{4}{*}{3} & Results management & Three & & \\
\hline & Viewing laboratory results & & & $x$ \\
\hline & Viewing imaging results & & $x$ & $x$ \\
\hline & Electronic images returned & & $x$ & $\times$ \\
\hline \multirow[t]{4}{*}{4} & Clinical decision support & Three & & \\
\hline & $\begin{array}{l}\text { Warnings of drug interactions } \\
\text { or contraindications provided }\end{array}$ & & & $x$ \\
\hline & \begin{tabular}{|c|}
$\begin{array}{c}\text { Out of range test levels } \\
\text { highlighted }\end{array}$ \\
\end{tabular} & & & $x$ \\
\hline & $\begin{array}{c}\text { Reminders regarding } \\
\text { guideline-based interventions } \\
\text { or screening }\end{array}$ & & & $x$ \\
\hline
\end{tabular}

Source: [8].

\section{Challenges in Implementation of ICT in Health}

[9] notes that the successful implementation of ICT and health programmes requires complex balancing of competing views and concerns of different stakeholders. Health policy makers would need to be convinced that initial investments in the new technology will yield the benefits promised while clinicians will view new technology with suspicion, fearing its challenge to their professional autonomy and status. On the other hand, patients are concerned about security and confidentiality of any of their electronically held health data. [10] observed that health system performance in developing countries is constrained by many factors including limited infrastructure, disease burden and shortage of health workers.

[11] observed that the shortage of health care workers in Africa is estimated at 800,000 and that it is difficult to recruit and retain such workers especially in rural areas. Further, in order to provide adequate coverage with primary care interventions and achieve Millennium Development Goals, it is recommended that provider to people ratio be at least 1:400 [12]. Conversely, the Kenyan ratio stands at 1:5000 [13].

According to HIS policy framework [5], the current health information systems in Kenya are designed and implemented with no or limited participation of those who are to ultimately operate them and there is inadequate involvement of those who are to use the information generated by the systems. In addition, existing HISs are highly fragmented with no linkages with other healthcare providers at various levels. This is because the design and implementation of the HISs does not facilitate integration of different sources of health information within the health system. Further, poor integration of vertical programs and administrative 


\section{International Journal of Science and Research (IJSR) \\ ISSN (Online): 2319-7064}

Index Copernicus Value (2015): 78.96 | Impact Factor (2015): 6.391

information into the routine HIS has resulted to lack of sharing of information among health care providers in the health system. Meaningful improvements can only be achieved as a result of provision of integrated information generated and used by all health care providers in Kenya.

\section{Methodology}

The study assessed the application of ICT in healthcare provision in low resource settings. A case study research strategy was adopted with specific focus on Kabarak University Health Center in Kenya. The study targeted 82 respondents stratified into healthcare providers, informaticians and patients. The health care providers' included doctors, clinical officers, nurses, records officers, laboratory technicians and pharmacists (Table 2). The study targeted patients who had at least one previous visit to the health centre given that they have an existing medical history at Kabarak University Health Centre. The population of this target category of patients was provided in terms of monthly patient loads.

Table 2: Target Population

\begin{tabular}{|c|c|}
\hline Category & Target Population \\
\hline Doctor & 2 \\
\hline Clinical Officer & 3 \\
\hline Nurse & 10 \\
\hline Pharmacist & 3 \\
\hline Laboratory Technician & 2 \\
\hline Records Personnel & 3 \\
\hline Patients & 58 \\
\hline Informatician & 1 \\
\hline TOTAL & 82 \\
\hline
\end{tabular}

Source: [14]

Thereafter, purposive sampling was used to draw out all the providers, informatician and patients targeted. Further, simple random sampling was used to draw out the 10 patients. Hence a total of 34 respondents were sampled as shown in Table 3

Table 3: Sampled Population

\begin{tabular}{|c|c|}
\hline Stratum & Sample Population \\
\hline Doctor & 2 \\
\hline Clinical Officer & 3 \\
\hline Nurse & 10 \\
\hline Pharmacist & 3 \\
\hline Laboratory Technician & 2 \\
\hline Records Personnel & 3 \\
\hline Patients & 10 \\
\hline Informatician & 1 \\
\hline Total & 34 \\
\hline
\end{tabular}

Source: [14]

Subsequently, data was collected from sampled respondents using interviews and questionnaires. Further, documentary reviews were employed to establish average monthly patient loads. This approach yielded both quantitative and qualitative data from the sampled case respondents. The qualitative data collected using interviews and open ended questions were analyzed thematically while quantitative data was analyzed descriptively. Tables were used to summarize and present the study results (Tables 4, 5 and 6)

\section{Analysis and Discussion of Results}

\subsection{Type of Systems used to Manage Health Information.}

The study sought to determine the type of systems used to manage health information at Kabarak University Health Centre and to this end responses were sought from records officers and informatician $\left(I_{1}\right)$. The findings are as illustrated in Tables 4 and 5 respectively.

Table 4: Type of systems used by Records Officer to keep information recorded in an episode of care

\begin{tabular}{|c|c|c|}
\hline Type of System & Number & $\%(\mathrm{~N}=3)$ \\
\hline Manual & 3 & 100 \\
\hline Computerised & 2 & 66.7 \\
\hline Mobile & 0 & 0 \\
\hline
\end{tabular}

NB: Table shows multiple responses

Source: [14]

The findings in Table 4 show that manual and computerized systems are the two main types of systems used at Kabarak University Health Centre with $100 \%$ (3) and $66.7 \%$ (2) responses respectively. Conversely, none of the record officers has ever used a mobile system to record information in an episode of care. This is in agreement with the findings hitherto which demonstrate that Kabarak University Health Centre employs a manual and an EMR in its provision of healthcare. Further, it is evident that the limited uptake of technology is as identified by the Kenyan Ministry of Health as a major challenge in application of ICTs in Health Care [5].

Table 5: Modules implemented Kabarak University Health Centre EMR

\begin{tabular}{|c|c|}
\hline Respondent & Modules implemented in the EMR \\
\hline \multirow[t]{27}{*}{$\mathrm{I}_{1}$} & "Reception \& Scheduling" \\
\hline & "Patient Management" \\
\hline & "Clinical \& Nursing”" \\
\hline & "Pharmacy" \\
\hline & "Laboratory Management" \\
\hline & "Reporting" \\
\hline & Features in the Reception and Scheduling Module \\
\hline & |"Patient appointment booking and honouring" \\
\hline & Features in the Patient Management Module \\
\hline & "Patient Registration" \\
\hline & "Patient Workflow" \\
\hline & "Billing and Finance" \\
\hline & Features in the Clinical and Nursing Module \\
\hline & "Diagnosis entry" \\
\hline & Features in the Pharmacy Module \\
\hline & "Receive Drug Prescription" \\
\hline & "Drug Dispensing”" \\
\hline & Features in the Laboratory Module \\
\hline & "Receive Lab request from doctors" \\
\hline & "Capture Lab Test Results" \\
\hline & "Bill for Tests" \\
\hline & "Send results to doctors" \\
\hline & Features in the Reporting Module \\
\hline & "Monthly Ministry Reports" \\
\hline & "Patient Medical Reports" \\
\hline & "Insurance Reports" \\
\hline & "Financial Reports" \\
\hline
\end{tabular}

Source: [14] 


\section{International Journal of Science and Research (IJSR) \\ ISSN (Online): 2319-7064 \\ Index Copernicus Value (2015): 78.96 | Impact Factor (2015): 6.391}

Table 5 shows that Kabarak University EMR consists of six modules, thus;

\section{- Reception \& Scheduling}

The Reception and Scheduling Module performs patient appointment, booking and honouring the appointments. This shows that the module only performs one function of the Health Information and Data functions of a fully functional EHR system (Table 1).

\section{- Patient Management}

The module has three features namely patient registration, patient work flow and finance (Table 5) showing that the module falls in the Health Information and data section of a fully functional EHR system (Table 1).

\section{- Clinical \& Nursing}

This module supports diagnosis entry which can entail clinical orders entry and medical history recording.

\section{- Pharmacy}

The module is used to receive prescription orders from the clinical and nursing module and dispense medications/drugs thereby prescribed (Table 5).

\section{- Reporting}

The module generates "Monthly Ministry Reports", "Patient Medical Reports", "Insurance Reports" and "Financial Reports" (Table 5). The Monthly Ministry Reports are consumed vertically by the Ministry of Health. The Patients Medical Reports is a brief reporting aggregate statistics which are relevant to the Health Centre Management. Since Insurance and Financial Reports are equally management reports, it is evident that the EMR concentrates on aggregates rather than horizontal information to providers and patients which enriches an episode of care. This confirms the limitations as alluded to in the Kenyan Government HIS Policy of 2009.

\subsection{Sections that have been computerized}

The findings in Table 4 indicate that only $66.7 \%$ of the sections within the facility have been computerised. Conversely, the findings in Table 5 shows that EHR functionalities (Table 1) have been implement as modules thus implying computerization of most sections within the facility. It can thus be inferred that all sections (records, pharmacy, laboratory and consultation) are computerised as confirmed by the informatician (Table 5) but that the record officers are only modular aware of their module in the EHR.

\subsection{Challenges inherent in the Healthcare Information System}

The study sought to establish the challenges with the current system of managing healthcare information from nurses, laboratory technicians, records officers and informatician. Their individual responses are as shown in Table 6.
Table 6: Challenges inherent in the Healthcare Information

\begin{tabular}{|c|c|}
\hline \multicolumn{2}{|r|}{ System } \\
\hline Respondent & Challenges \\
\hline $\mathrm{N}_{1}$ & $\begin{array}{l}\text { - "Receiving false information which alters the } \\
\text { - diagnosis." } \\
\text { - "Poor handwriting, difficult to comprehend." } \\
\text { - "Power failure." }\end{array}$ \\
\hline $\mathrm{N}_{2}$ & $\begin{array}{l}\text { - "Storage of records: - No electronic capturing on } \\
\text { data storage and retrieval." }\end{array}$ \\
\hline $\mathrm{N}_{3}$ & $\begin{array}{l}\text { - "No computers for capturing the patients records } \\
\text { for future reference." }\end{array}$ \\
\hline $\mathrm{N}_{4}$ & $\begin{array}{l}\text { - "Faulty information:- some patients may lie } \\
\text { about information." } \\
\text { - "Delay in system for electronic medical record } \\
\text { system." }\end{array}$ \\
\hline $\mathrm{N}_{5}$ & $\begin{array}{l}\text { - "Language barrier." } \\
\text { - "Difficult patients." } \\
\text { - "Holding vital information., }\end{array}$ \\
\hline $\mathrm{N}_{6}$ & $\begin{array}{l}\text { - "Language barrier." } \\
\text { - "Children who cannot speak." } \\
\text { - "When net is low." }\end{array}$ \\
\hline $\mathrm{N}_{7}$ & $\begin{array}{l}\text { - "Accessibility of patients records-i.e. when there } \\
\text { is no internet." } \\
\text { - "Language barrier." } \\
\text { - "Uncooperative patient." }\end{array}$ \\
\hline $\mathrm{N}_{8}$ & $\begin{array}{l}\text { - "Comatosed patients." } \\
\text { - "Language barrier." } \\
\text { - "Non cooperative patients.", } \\
\text { - "In recording-lack of books, low net." }\end{array}$ \\
\hline $\mathrm{N}_{9}$ & - "Time consumption when using both." \\
\hline $\mathrm{N}_{10}$ & ge barrier." \\
\hline $\mathrm{LT}_{1}$ & $\begin{array}{l}\text { - "When there is no power or internet we are not } \\
\text { able to use electronic medical record system." }\end{array}$ \\
\hline $\mathrm{LT}_{2}$ & $\begin{array}{l}\text { - "When the internet services are low thus creating } \\
\text { problems when reporting the results." }\end{array}$ \\
\hline $\mathrm{I}_{1}$ & $\begin{array}{l}\text { - "No reliable or credible source of ICD-10 } \\
\text { - "Listings" } \\
\text { - "Disjointed modules within the system resulting } \\
\text { in manual uploading of data in CSV" } \\
\text { - "User activity leading to wrong entries" } \\
\text { - "Poor Network connectivity leading to } \\
\text { - "Powntimes" } \\
\text { - "Danual system" } \\
\text { - dispauses outages, - the fall back is the } \\
\text { - "Non-clear policy on private devices" }\end{array}$ \\
\hline $\mathrm{RO}_{1}$ & $\begin{array}{l}\text { - "Patient's ignorance on the return dates, that is } \\
\text { either they come before or after their dates. It } \\
\text { may not be considered by the patient as of } \\
\text { importance." }\end{array}$ \\
\hline $\mathrm{RO}_{2}$ & $\begin{array}{l}\text { - "Power shortage." } \\
\text { - "Lack of network." }\end{array}$ \\
\hline $\mathrm{RO}_{3}$ & - "Power shortage." \\
\hline
\end{tabular}

Source: [14] 


\section{International Journal of Science and Research (IJSR) \\ ISSN (Online): 2319-7064}

Index Copernicus Value (2015): 78.96 | Impact Factor (2015): 6.391

Table 6.1: Key

\begin{tabular}{|c|c|c|}
\hline $\mathrm{S} / \mathrm{N}$ & Respondents & Represents \\
\hline 1 & $\begin{array}{c}\mathrm{N}_{1}, \mathrm{~N}_{2}, \mathrm{~N}_{3}, \mathrm{~N}_{4}, \mathrm{~N}_{5}, \mathrm{~N}_{6}, \mathrm{~N}_{7}, \\
\mathrm{~N}_{8} \mathrm{~N}_{8} \mathrm{~N}_{10}\end{array}$ & The ten respective nurses \\
\hline 2 & $\mathrm{LT}_{1 .} \mathrm{LT}_{2}$ & $\begin{array}{c}\text { The two respective laboratory } \\
\text { technicians }\end{array}$ \\
\hline 3 & $\mathrm{I}_{1}$ & The Informatician \\
\hline 4 & $\mathrm{RO}_{1}, \mathrm{RO}_{2}, \mathrm{RO}_{3}$ & $\begin{array}{c}\text { The three respective records } \\
\text { officers }\end{array}$ \\
\hline
\end{tabular}

Source: [14]

From the findings in Table 6 , the researcher inferentially classified the challenges encountered by the specified respondents thus:

- Communication challenges as demonstrated by $\mathrm{N}_{1}$ as "poor handwriting which is difficult to comprehend" and by $\mathrm{N}_{5}, \mathrm{~N}_{6}, \mathrm{~N}_{7}$ and $\mathrm{N}_{8}$ as "language barrier", "children who cannot speak". This is in agreement with [15] who observed that paper based systems supporting clinical care have high rates of failure in retrieval and illegibility and that human memory based medicine is increasingly unreliable.

- Technological challenges which are brought about by power failure as demonstrated by $\mathrm{N}_{1}, \mathrm{LT}_{1}, \mathrm{RO}_{2}$ and $\mathrm{RO}_{3}$ and confirmed by $\mathrm{I}_{1}$ "Power loss causes outages, - the fall back is the manual system" or network connectivity as indicated by $\mathrm{N}_{4}, \mathrm{~N}_{6}, \mathrm{~N}_{7}, \mathrm{~N}_{8} \mathrm{LT}_{1}, \mathrm{R}_{2}$ and $\mathrm{R}_{3}$ and corroborated by $\mathrm{I}_{1}$ "Poor Network connectivity leading to downtimes". There is also lack of computers for data capture and storage as indicated by $\mathrm{N}_{2}$ and $\mathrm{N}_{3}$ in agreement with the HIS Policy of 2009 which notes that there exists limited availability of requisites skills, equipment and IT illiteracy inhibiting integration of Information Technology to health information. In addition, other technical challenges indicated by $\mathrm{I}_{1}$ included "Disjointed modules within the system resulting in manual uploading of data in CSV" and "Difficulty maintaining stock levels due to disparate systems"

It is evident from $\mathrm{I}_{1}, \mathrm{RO}_{2}, \mathrm{RO}_{3}$ and $\mathrm{N}_{1}$ that power outages lead to the unavailability of the EMR hence the fallback by the respective respondents to the manual system.

- Integrity information as demonstrated by N1 where they receive "false information which alters the diagnosis" or "some patients who provide false information" as indicated by $\mathrm{N}_{4}$.

- Confidentiality/privacy as demonstrated by $\mathrm{N}_{5}$ as "holding vital information". This could imply that the health care provider may be concerned about legal liability [15], in the event that he/she divulges the information that is within his/her confines.

- Ignorancellack of information to make right decision as indicated by $\mathrm{RO}_{1}$ as "patient ignorance on return dates".

- Challenges of mining information from patients as demonstrated by $\mathrm{N}_{7}$ and $\mathrm{N}_{8}$ as "uncooperative patients". This shows that a patient may not be willing or fears to divulge some information to the nurse and this concurs with [15] who noted that patients' have concerns about information sharing and possible loss of privacy.

- Policy Level Challenges as demonstrated by $\mathrm{I}_{1}$ "No reliable or credible source of ICD-10 Listings". This shows that Kabarak University Health Centre is yet to benefit from the domestication of ISO-Health Informatics Standards [16] as adopted by Kenya Bureau of Standards.
Further, existing policies are lacking in clarity as indicated by $\mathrm{I}_{1}$ "Non-clear policy on private devices".

\section{Conclusion}

Both manual and computerised systems are under use by Kabarak University Health Centre to record/capture patient information in an episode of care. Further, the study findings showed that records, consultation, laboratory, and pharmacy sections have been computerized. It was established that ICT is being employed in the provision of healthcare in Low and Middle income countries but that challenges exist in their adoption and use vide:

- Communication challenges such as poor handwriting which is difficult to comprehend (Table 6).

- Technological challenges brought about by power failure, poor network connectivity, lack of computers for data capture and storage, disjointed EMR modules and disparate systems (Table 6).

- Provision of false information by patients which alters diagnosis (Table 6)

- Confidentiality/privacy issues arising from the fact that the providers hold vital information (Table 6)

- Patients' ignorance for example by ignoring return dates (Table 6).

- Patients being uncooperative in provision of information (Table 6).

- Policy challenges such as unclear policy on private ICT devices (Table 6).

- Reporting Challenges being generation vertical management reports rather than horizontal patient centred reports( Table 5)

\section{Recommendations}

Based on the findings, the study recommends:

\subsection{Increased Investments in ICT Infrastructure}

Whereas the study established that there is significant adoption of ICT in healthcare provision, it also evidenced existence of challenges that are brought about by the low resource setting of the study area. There is need to further invest in ICTs and their enabling infrastructure for instance electrical power availability and reliability.

\subsection{Adoption of Mobile Technology to Further Accessibility of Healthcare Information}

The study established that Kabarak University Health Centre employs manual and computerized systems in capturing, processing, storage, exchange and use of patient related data. To enhance availability and accessibility of the afore mentioned health information by patients and providers, it is recommended that the healthcare service sector adopts mobile technology.

\subsection{Enactment of Enabling HIS Policies and Awareness Creation}

The current challenges on privacy and confidentiality were observed to be as a result of inadequate HIS policies and/or

\section{Volume 6 Issue 7, July 2017 www.ijsr.net}




\section{International Journal of Science and Research (IJSR) \\ ISSN (Online): 2319-7064}

Index Copernicus Value (2015): 78.96 | Impact Factor (2015): 6.391

lack of awareness of existing policies defining use of ICTs in healthcare service delivery. The study proposes that the government engages all stakeholders in creating awareness on existing policies as well as enact policies to govern use of private devices in accessing health information.

\section{References}

[1] K. Coleman, R. Reid \& Safety Net Medical Home Initiative, "Continuous and Team-Based Healing Relationships Implementation Guide”, Improving Patient Care Through Teams, 2010.

[2] J. Dzenowagis, G. Kernen \& World Health Organization, "Connecting for health: global vision, local insight", Report for the World Summit on the Information Society, 2005.

[3] World Bank, "World Development Report", Equity and Development - Washington DC, 2006. [Online]. Available: http://openknowledge.worldbank.org/handle/10986/598 8

[4] American Medical Association, "Health Information Technology", 2015. [Online]. Available: www.amaassn.org.

[5] OECD, "Improving Health Sector Efficiency", The Role of Information Communication Technologies, 2010.

[6] GoK, "Health Information System Policy", 2009.

[7] GoK, "Standard and Guidelines for Electronic Medical Record Systems in Kenya", 2010. [Online]. Available: www.eaphln-ecsahc.org/kenya/?wpfb_dl=36 .

[8] C. M. DesRoches, E. G. Campbell, S. R. Rao, K. Donelan, T. G. Ferris, A. Jha \& D. Blumenthal, "Electronic health records in ambulatory care-a national survey of physicians", New England Journal of Medicine, CCCLIX (1), pp.50-60, 2008.

[9] A. Chetley, J. Davies, B. Trude, H. McConnell \& R. Ramirez, "Improving health connecting people", The role of ICTs in the health sector of developing countries, 2006.

[10] J. G. Kahn, J. S. Yang, \& J. S. Kahn, “"Mobile' health needs and opportunities in developing countries", Health Affairs, XXIX (2), pp.252-258, 2010.

[11] R. M. Scheffler, C. B. Mahoney, BD. Fulton, M. R. Dal $\mathrm{Poz} \&$ AS. Preker, "Estimates of health care professional shortages in sub-Saharan Africa by 2015", Health affairs, XXVIII(5), pp.849-862, 2009.

[12] WHO, "World Health Report", Working together for health, 2009.

[13] WHO \& OECD, "Global Health Workforce Statistics", 2011. [Online]. Available: http://data.worldbank.org/indicator/SH.MED.PHYS.ZS.

[14]S. T. Mbugua, "A Mobile Phone Based Clinical Summaries Model for Health Care Providers and Patients", Unpublished Moi University Thesis, 2017.

[15]L. C. Burton, G. F. Anderson, \& I.W. Kues, "Using electronic health records to help coordinate care", Milbank Quarterly, LXXXII (3), pp. 457-481, 2004. [Online].

Available: http://www.jstor.org/stable/4150507.

[16] International Organization for Standardization (ISO/TC 215:2005), "ISO Catalogue", Health Informatics Technical Committee, 2005.

\section{Author Profile}

Samuel T. Mbugua is an Msc in Information Technology finalist in Moi University (2017). He was awarded a Bsc degree in Computer Science by Egerton University (2005) and a CCNA Certified Professional (2006). He has over 10 years experience in Software Design and Development being a developer for OpenMRS, OpenDataKit and mUzima Open Source Community Projects. Since 2010 he has been an Information Systems Support officer at Moi University largely involved in the implementation of Financial Management Systems and other systems within the University. Between 2009 and 2011 he was attached to Moi Teaching \& Referral Hospital-AMPATH where he was involved in development and implementation of Electronic Health Systems with special focus on Mobile Technology. Between 2005 and 2008 he worked at Kabarak University first as a Systems Administrator and later as ICT Manager. Samuel has great interests in Systems Security, Open Source Communities Contribution and Management, Health Information Systems and Network Administration.

Prof. David M. Gichoya is a holder of a PhD in Information and Computer Science from Loughborough University, UK (2007). He did his Msc. in Computer Science and Applications at Shaghai University China (1996). He was awarded a B.Ed in Business Studies by Kenyatta University in 1988. He is an Associate Professor at the Department of Information Technology- School of Information Sciences-Moi University where he previously served as Senior Lecturer and a Lecture. Currently he is the Associate Dean at the School of Information Sciences - Moi University.

Dr. Damaris N. Odero holds a $\mathrm{PhD}$ in Library and Information Studies from the University of Botswana (2003), an MPhil. in Information Sciences (Library and Information Studies), Moi University (1995) and a Bsc. in Information Sciences, Moi University (1992). She is currently a Senior Lecturer and the Head of Department of Library, Records Management and Information Studies at the School of Information Sciences. She is an accomplished scholar who has published widely in the greater field of information sciences. 